\title{
Viscum album extract (Helixor-M) treatment for thoracic duct injury after modified radical neck dissection: a case report
}

\author{
Chai-Won $\mathrm{Kim}^{1} \wedge$, Jeong-Soo Kim ${ }^{2}$, Ae-Hee Lee ${ }^{3}$, Yong-Seok Kim ${ }^{1 \wedge}$ \\ ${ }^{1}$ Department of Surgery, Uijeongbu St. Mary's Hospital, College of Medicine, The Catholic University of Korea. 271, Cheonbo-ro, Uijeongbu- \\ si, Gyenggi-do, Republic of Korea; ${ }^{2}$ Department of Surgery, Seoul St. Mary's Hospital, college of Medicine, The Catholic University of Korea. \\ 222, Banpo-daero, Seocho-gu, Seoul, Republic of Korea; ${ }^{3}$ General Surgery Unit, Uijeongbu St. Mary's Hospital, college of Medicine, The Catholic \\ University of Korea. 271, Cheonbo-ro, Uijeongbu-si, Gyenggi-do, Republic of Korea \\ Correspondence to: Yong-Seok Kim, MD, PhD. Department of Surgery, Uijeongbu St. Mary's Hospital, college of Medicine, The Catholic University \\ of Korea. 271, Cheonbo-ro, Uijeongbu-si, Gyenggi-do 11765, Republic of Korea. Email: dydtjr97@catholic.ac.kr.
}

\begin{abstract}
Chyle leakage after modified radical neck dissection is a rare condition that could be occasionally life-threatening if untreated. We report the first case of successful management of a thoracic duct injury using Viscum album extract (Helixor-M). A 54-year-old woman diagnosed with papillary thyroid cancer of the right lobe of the thyroid with metastasis to cervical lymph node levels II-VI, bilaterally, underwent total thyroidectomy and modified radical neck dissection. Three days postoperatively, the surgical team identified a thoracic duct injury due to drainage of chyle from the Jackson-Pratt drain inserted in the right side of the patient`s neck. Various medical treatments (octreotide, withdrawal of enteral feeding, and total parenteral nutrition) and surgical treatments [lymphatic ligation of cervical lymph node level IV and negative pressure wound therapy (vacuum-assisted closure)] were performed, but the drainage persisted. Viscum album extract (Helixor-M) was then injected through the drain. The dose of Viscum album extract was increased while being cautious of its adverse effects, such as nausea, vomiting, erythema, induration at the injection site, and flu-like symptoms. The injection was effective in stopping the drainage and the patient's condition improved, without recurrence. The patient was discharged on the $64^{\text {th }}$ postoperative day without any further complications. Our results suggest that treatment of thoracic duct injury after neck surgery with Viscum album extract (Helixor-M) may be a novel, less invasive alternative approach to treat cases resistant to standard treatments.
\end{abstract}

Keywords: Thoracic duct injury; radical neck dissection; chyle leakage; Viscum album; Helixor-M

Submitted Jul 26, 2020. Accepted for publication Nov 27, 2020.

doi: $10.21037 /$ gs-20-629

View this article at: http://dx.doi.org/10.21037/gs-20-629

\section{Introduction}

Chyle leakage is an uncommon but potentially lifethreatening complication of neck surgery (1). Iatrogenic thoracic duct injury occurs in $0.5-1.4 \%$ of thyroidectomies and $2-8 \%$ of neck dissections (2). A previous study reported that the incidence of chyle leakage was $4.5-8.3 \%, 1.4 \%$ of which are seen in patients with papillary thyroid cancer who undergo total thyroidectomy with neck dissections (3). Most cases of chyle leakage are known to occur after left- sided neck surgeries, with only about $25 \%$ of leakages occurring after right-sided neck surgery (2). Chyle leakage may be identified intraoperatively or postoperatively (2). If chyle leakage is found intraoperatively, it must be repaired immediately. Postoperatively, a sudden increase in the output of the drain after eating a fatty meal should raise suspicion of a chyle leakage $(1,2)$. In such cases, the output of the drain would be creamy or milky $(2,4)$. On physical examination the neck may exhibit lymphedema, erythema,

^ ORCID: Chai-Won Kim 0000-0001-9465-1151; Yong-Seok Kim 0000-0003-4894-5006 

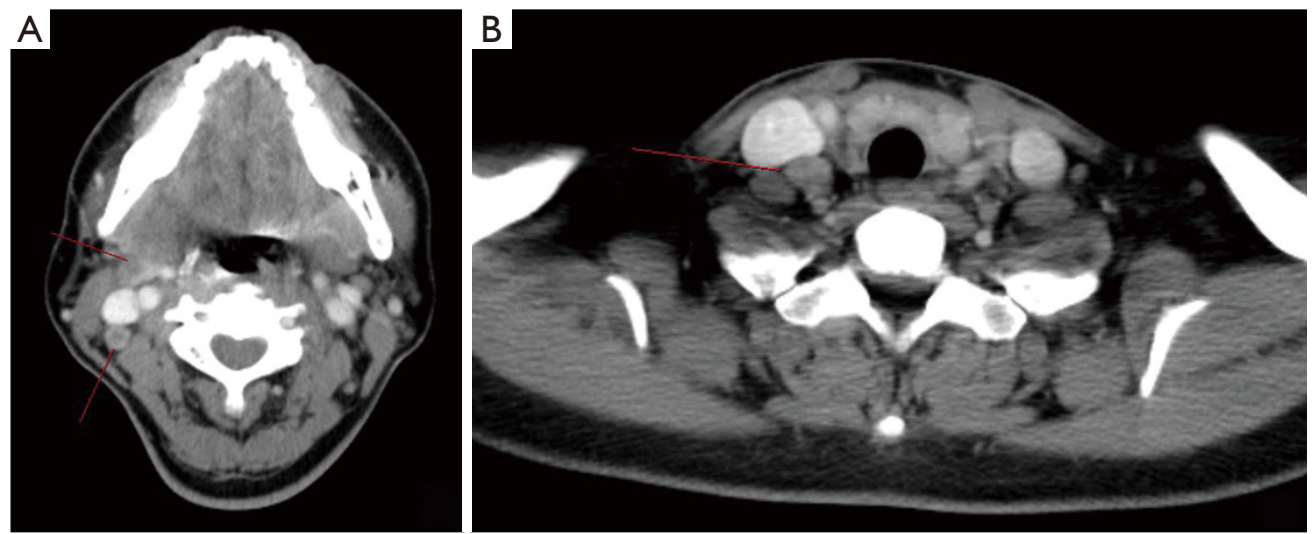

Figure 1 Neck computed tomography (2019.01.18). Bilateral thyroid malignant nodules with multiple lateral and central metastatic lymph nodes through right level II, III and bilateral level V, VI.

or there may be a palpable cystic mass in the supraclavicular region (2). Chyle leakage can be diagnosed clinically (2). This diagnosis can be confirmed by laboratory assessment of the triglycerides concentration of the discharging fluid which is usually above $100 \mathrm{mg} / \mathrm{dL}$ in cases of chyle leakage (4). Chyle leakage can result in protein loss, malnutrition, dehydration, electrolyte disturbances, poor wound healing, coagulopathy, and immunosuppression $(2,4)$. Since it is potentially life-threatening, prompt diagnosis and treatment are essential (1). Conservative treatment is recommended as the first approach, and includes a medium-chain triglyceride diet, total parenteral nutrition, somatostatin, and octreotide medication $(2,5)$. Thoracic duct ligation and embolization are also considered $(2,6)$. We have experienced about 30 cases of chyle leakage so far. Most cases were resolved with conservative and while others required surgical treatment. However, if chyle leakage is not resolved by a combination of conventional treatments, alternatives must be explored. We considered Viscum album extract (Helixor-M) as an alternative sclerosing agent for the treatment of chyle leakage. We report a case of chyle leakage that was successfully treated using $V$. album extract.

We present the following case in accordance with the CARE reporting checklist (available at http://dx.doi. org/10.21037/gs-20-629).

\section{Case presentation}

A 54-year-old woman with no relevant medical and family history presented with a submandibular mass and was diagnosed with papillary thyroid carcinoma of the right thyroid lobe with metastasis to the cervical lymph node levels
II-VI, bilaterally (Figure 1). The patient underwent total thyroidectomy and modified radical neck dissection on January 28, 2019. Three days postoperatively, the surgeon identified a creamy-colored fluid being drained from the Jackson-Pratt (JP) drain inserted in the right side of the patient's neck and this was suspected to be chyle leakage due to thoracic duct injury. The chyle output from the JP drain was 100-200 mL/day, but there was a considerable amount of oozing around the drain. The patient underwent lymphatic ligation of cervical lymph node level IV on February 7. However, on February 8, the wound was opened, and another silastic drain was inserted due to swelling of the patient's neck (Figure 2). Conservative therapy with octreotide was commenced, enteral feeding was withheld, and total parenteral nutrition was administered. Nevertheless, the drainage persisted, and negative pressure wound therapy (vacuum-assisted closure) was attempted four times. The patient's condition improved and he commenced enteral feeding on February 26; the patient was also placed on a lowfat diet. The next day, $240 \mathrm{~mL}$ of chyle was drained, and an additional $590 \mathrm{~mL}$ drained the next day, necessitating the need for alternative treatment. The surgical team injected $100 \mathrm{mg}$ of $V$. album extract via the drain from February 28 to March 3; $200 \mathrm{mg}$ from March 5 to $14 ; 300 \mathrm{mg}$ from March 15 to 21; and $400 \mathrm{mg}$ on March 22. The dose was increased while being cautious of adverse effects such as nausea, vomiting, erythema, induration at the injection site, and flu-like symptoms. During this period, enteral feeding was withered, and the patient was placed on total parenteral nutrition (Figure 3). Eventually, the drainage stopped, and the patient's condition improved. The patient started eating a low-fat diet again on March 15. The team removed the drain catheter on April 1, and the patient was discharged on the $64^{\text {th }}$ postoperative day 


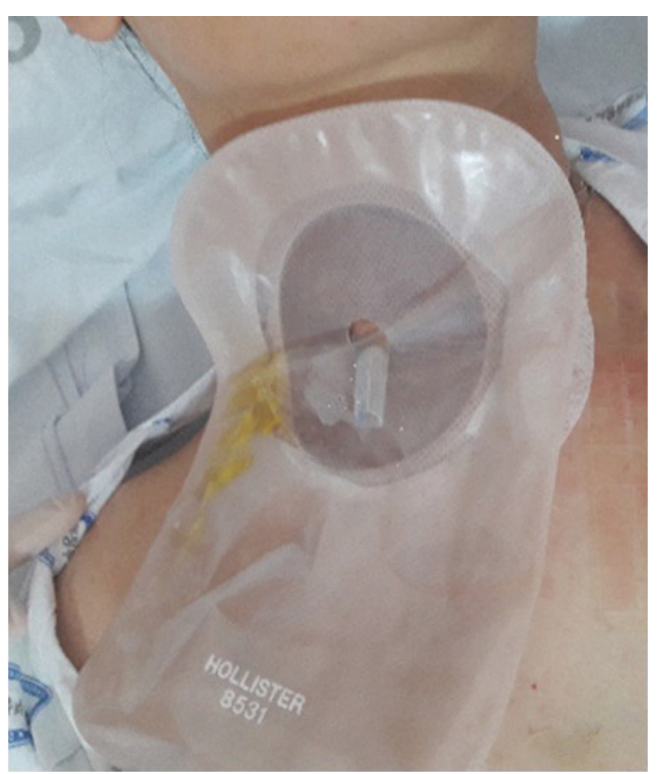

Figure 2 Silastic drain insertion due to the patient's neck swelling. Stomy pouch connection because of high output chyle leakage volume.

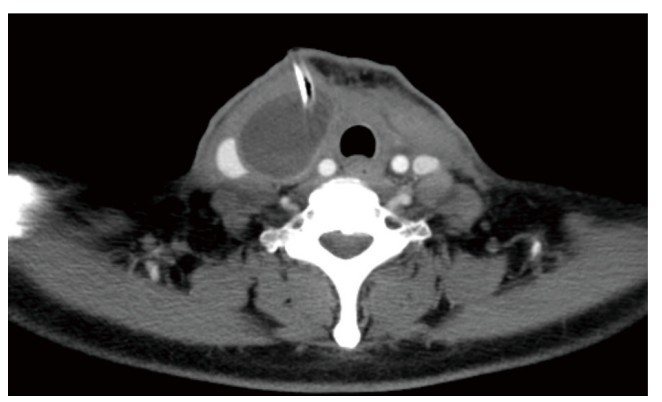

Figure 3 Neck computed tomography (2019.03.25). About $4 \mathrm{~cm} \times$ $3 \mathrm{~cm} \times 5.5 \mathrm{~cm}$ sized oval cystic lesion at right operation site. Drain catheter insertion state. -> Rule out: postoperative fluid collection.

without any further complications. After discharge, the surgical team followed up the patient for 15 months. The patient was well managed without recurrence and complications.

All procedures performed in studies involving human participants were in accordance with the ethical standards of the institutional and/or national research committee(s) and with the Helsinki Declaration (as revised in 2013). Written informed consent was obtained from the patient.

\section{Discussion}

Chylous fistula is a postoperative complication of neck surgery, especially radical neck dissection involving cervical lymph node levels IV, V (7). Due to its proximity to the internal jugular vein and thin vessel wall, the thoracic duct is particularly susceptible to unintentional injury during neck dissections (2). The patient had metastasis to cervical lymph node levels IV and V, bilaterally, and this contributed to a high chance of thoracic duct damage.

Chyle leakage may be categorized according to the volume of chyle drained, the volume drained also determines the choice of treatment. Chyle leakage of $<500 \mathrm{~mL} /$ day is considered to be low-output and can be effectively treated with conservative approaches. High-output fistulas producing chyle $>500 \mathrm{~mL} /$ day tend to be unresponsive to conservative management and are treated surgically $(2,7)$.

The first-line treatment for chyle leakage is conservative management that consists of pressure dressing, suction drainage, dietary modification, and administration of somatostatin, octreotide, or orlistat. Somatostatins and octreotide are known to be effective medications and are widely used (8). Most chyle fistulas can be managed successfully using conservative treatment (9). A previous study reported that about $81.8 \%$ cases of chyle fistulas after neck dissection were successfully treated with nonsurgical methods (10).

If a chyle drainage remains uncontrolled after conservative care, surgeons should consider surgical exploration of the thoracic duct. A previous study recommended surgery for chyle leaks of $>1,000 \mathrm{~mL} /$ day for more than five days, or persistent leaks lasting more than two weeks despite conservative treatment (11).

Recently, other alternative methods have been reported, such as muscle flap or selective embolization, and an ultrasound-guided intranodal lymphangiography $(9,12)$. Treatment methods using chemical agents have been introduced. Chemical pleurodesis using povidone-iodine in patients with congenital idiopathic chylothorax, talcinduced pleurodesis, other sclerosing agents, such as OK432 , tetracycline, and pseudomonas aeruginosa-mannose sensitive hemagglutinin injection have been reportedly used $(2,11,13,14)$.

In this case, the surgical team tried various methods, including conservative and operative management none of which were effective. Compared to other previous studies, they attempted to treat the patient by injecting a $V$. album extract through the drain and this stopped the drainage without recurrence.

$V$. album is a species of mistletoe that occurs predominantly in Europe (15). Helixor ${ }^{\circledR}$ is a brand name for mistletoe extracts in Europe (16). Two components of mistletoe, namely viscotoxins and lectins, have been known to kill cancer cells and 
stimulate immune system cells (17). $V$. album extract is widely used for treatment in the field of oncology (16). It is known to stimulate the immune system, improve survival, enhance quality of life, and decrease the side effects of chemotherapy and radiotherapy (18). Furthermore, V. album extract has been used as an alternative sclerosing agent for pleurodesis and this has been reported to be efficient in treating malignant pleural effusion in cases of lung cancer and congenital chylothorax $(18,19)$.

To the best of our knowledge, this is the first reported case of the successful treatment of thoracic duct injury using $V$. album extract injection. Although further research is required to determine the clinical efficacy of $V$. album extract, it is a minimally invasive treatment that may be a novel treatment alternative for patients with chyle leakage who are unresponsive to conventional treatments.

\section{Acknowledgments}

Funding: None.

\section{Footnote}

Reporting Checklist: The authors have completed the CARE reporting checklist. Available at http://dx.doi.org/10.21037/ gs-20-629

Conflicts of Interest: All authors have completed the ICMJE uniform disclosure form (available at http://dx.doi. org/10.21037/gs-20-629). The authors have no conflicts of interest to declare.

Ethical Statement: The authors are accountable for all aspects of the work in ensuring that questions related to the accuracy or integrity of any part of the work are appropriately investigated and resolved. All procedures performed in studies involving human participants were in accordance with the ethical standards of the institutional and/or national research committee(s) and with the Helsinki Declaration (as revised in 2013). Written informed consent was obtained from the patient. The study was approved by the Institutional Review Board (IRB) of the Uijeongbu St. Mary's Hospital (No. UC20ZISI0048).

Open Access Statement: This is an Open Access article distributed in accordance with the Creative Commons Attribution-NonCommercial-NoDerivs 4.0 International License (CC BY-NC-ND 4.0), which permits the non- commercial replication and distribution of the article with the strict proviso that no changes or edits are made and the original work is properly cited (including links to both the formal publication through the relevant DOI and the license). See: https://creativecommons.org/licenses/by-nc-nd/4.0/.

\section{References}

1. Ilczyszyn A, Ridha H, Durrani AJ. Management of chyle leak post neck dissection: A case report and literature review. J Plast Reconstr Aesthet Surg 2011;64:e223-30.

2. Delaney SW, Shi H, Shokrani A, et al. Management of Chyle Leak after Head and Neck Surgery: Review of Current Treatment Strategies. Int J Otolaryngol 2017;2017:8362874.

3. Roh JL, Yoon YH, Park CI. Chyle leakage in patients undergoing thyroidectomy plus central neck dissection for differentiated papillary thyroid carcinoma. Ann Surg Oncol 2008;15:2576-80.

4. Polistena A, Vannucci J, Monacelli M, et al. Thoracic duct lesions in thyroid surgery: An update on diagnosis, treatment and prevention based on a cohort study. Int J Surg 2016;28:S33-7.

5. Costa KM, Saxena AK. Surgical chylothorax in neonates: management and outcomes. World J Pediatr 2018;14:110-5.

6. Kariya S, Nakatani M, Yoshida R, et al. Embolization for Thoracic Duct Collateral Leakage in High-Output Chylothorax After Thoracic Surgery. Cardiovasc Intervent Radiol 2017;40:55-60.

7. Belloso A, Saravanan K, de Carpentier J. The community management of chylous fistula using a pancreatic lipase inhibitor (orlistat). Laryngoscope 2006;116:1934-5.

8. Swanson MS, Hudson RL, Bhandari N, et al. Use of Octreotide for the Management of Chyle Fistula Following Neck Dissection. JAMA Otolaryngol Head Neck Surg 2015;141:723-7.

9. Polistena A, Monacelli M, Lucchini R, et al. Surgical morbidity of cervical lymphadenectomy for thyroid cancer: A retrospective cohort study over 25 years. Int J Surg 2015;21:128-34.

10. Ahn D, Sohn JH, Jeong JY. Chyle Fistula After Neck Dissection: An 8-Year, Single-Center, Prospective Study of Incidence, Clinical Features, and Treatment. Ann Surg Oncol 2015;22:S1000-6.

11. Anestis N, Christos FC, Ioannis P, et al. Thoracic duct injury due to left subclavicular vein catheterization: A new conservative approach to a chyle fistula using biological 
glue. Int J Surg Case Rep 2012;3:330-2.

12. Chen CY, Chen YH, Shiau EL, et al. Therapeutic role of ultrasound-guided intranodal lymphangiography in refractory cervical chylous leakage after neck dissection: Report of a case and review of the literature. Head Neck 2016;38:E54-60.

13. Brissaud O, Desfrere L, Mohsen R, et al. Congenital idiopathic chylothorax in neonates: chemical pleurodesis with povidone-iodine (Betadine). Arch Dis Child Fetal Neonatal Ed 2003;88:F531-3.

14. Chen Q, Zou X, Ma Y, et al. Pseudomonas aeruginosamannose sensitive hemagglutinin injection therapy for the treatment of chyle fistula following neck dissection. Head Neck 2020;42:725-31.

15. Huber R, Schlodder D, Effertz C, et al. Safety of intravenously applied mistletoe extract - results from a phase I dose escalation study in patients with advanced

Cite this article as: Kim CW, Kim JS, Lee AH, Kim YS. Viscum album extract (Helixor-M) treatment for thoracic duct injury after modified radical neck dissection: a case report. Gland Surg 2021;10(2):832-836. doi: 10.21037/gs-20-629 cancer. BMC Complement Altern Med 2017;17:465.

16. Horneber MA, Bueschel G, Huber R, et al. Mistletoe therapy in oncology. Cochrane Database Syst Rev 2008;2008:CD003297.

17. Steele ML, Axtner J, Happe A, et al. Adverse Drug Reactions and Expected Effects to Therapy with Subcutaneous Mistletoe Extracts (Viscum album L.) in Cancer Patients. Evid Based Complement Alternat Med 2014;2014:724258.

18. Cho HJ, Na KJ, Kim DW, et al. Chemical pleurodesis using a Viscum album extract in infants with congenital chylothorax. Eur J Pediatr 2014;173:823-6.

19. Lee YG, Jung I, Koo DH, et al. Efficacy and safety of Viscum album extract (Helixor-M) to treat malignant pleural effusion in patients with lung cancer. Support Care Cancer 2019;27:1945-9. 